\title{
Baseline Serum Magnesium Level and Its Variability in Maintenance Hemodialysis Patients: Associations with Mortality
}

\author{
Lingping Wu Kedan Cai Qun Luo Lailiang Wang Yue Hong \\ Department of Nephrology, Ningbo No. 2 Hospital, School of Medicine, Ningbo University, \\ Ningbo, China
}

\section{Keywords}

Magnesium · Maintenance hemodialysis patients · Variability · Mortality

\begin{abstract}
Background/Aims: The study aimed at investigating the impact of serum magnesium (Mg) baseline level and its variability on mortality in maintenance hemodialysis (MHD) patients. Methods: Eligible patients receiving regular MHD at Ningbo No. 2 Hospital between January 2009 and August 2016 were enrolled and follow-ups were conducted afterwards until death or transplantation. General information, laboratory results, and outcomes of subjects were collected. The relationship between baseline serum $\mathrm{Mg}$ level, its coefficient of variation (CV), and all-cause mortality and cardiovascular disease mortality were assessed, respectively. Subjects were divided into groups in 2 manners: by serum $\mathrm{Mg}$ level (lower $\mathrm{Mg}$ group: serum $\mathrm{Mg}$ $<1.00 \mathrm{mmol} / \mathrm{L}$, higher $\mathrm{Mg}$ group: serum $\mathrm{Mg} \geq 1.00 \mathrm{mmol} / \mathrm{L}$ ) and by serum $\mathrm{Mg} \mathrm{CV}$ (high variation group: $C V \geq 0.149 \mathrm{mmol} / \mathrm{L}$, middle variation group: $0.114 \mathrm{mmol} / \mathrm{L} \leq \mathrm{CV}<0.149 \mathrm{mmol} / \mathrm{L}$, and low variation group: $\mathrm{CV}<0.114 \mathrm{mmol} / \mathrm{L}$ ). Results: $169 \mathrm{MHD}$ patients were recruited in the study, with mean serum $\mathrm{Mg} 1.00 \pm 0.18 \mathrm{mmol} / \mathrm{L}$, average age $60.20 \pm 15.64$ years, and median dialysis duration 37.00 (18.30, 77.97) months. During the follow-up, 69 (40.83\%) patients died, 24 (34.78\%) of which died due to cardiovascular disease. Comparing the two groups, patients in the lower Mg group had a higher all-cause mortality (50.00 vs. 29.33\%, $p=0.007$ ). The multivariate Cox regression analysis suggested that lower $\mathrm{Mg}$ level was an independent factor for all-cause mortality as well as cardiovascular mortality (HR = 13.268, 95\% Cl 6.23428.237, $p<0.001 ; \mathrm{HR}=12.702,95 \% \mathrm{Cl} 3.737-43.174, p<0.001$, respectively). However, there were no significant statistical differences of all-cause and cardiovascular mortality among
\end{abstract}

L.W. and K.C. are the first co-authors. They contributed equally to this work. 
these three groups concerning $\mathrm{Mg}$ variation. And in the univariate and multivariate Cox regression analysis, serum magnesium CV was not the independent factor for all-cause mortality and cardiovascular mortality. Conclusions: The lower baseline serum magnesium level was associated with all-cause and cardiovascular mortality in MHD patients. However, the variability of magnesium level was not independently associated with the risk of death and further studies need to be conducted.

(C) 2019 The Author(s)

Published by S. Karger AG, Basel

\section{Introduction}

The all-cause mortality rate of patients on dialysis in 2015 was 174.4 deaths per 1,000 patient years, much higher than that in the general population [1]. Electrolyte disorder is the most common etiology of mortality in the maintenance hemodialysis (MHD) patients [2-3].

Magnesium (Mg) is the second abundant intracellular cation which plays a vital role in the regulation of vascular tone, heart rhythm, and platelet-activated thrombosis [4]. In the general population, low serum Mg level has been associated with higher risk of hypertension, type 2 diabetes mellitus, cardiac arrhythmia, cardiovascular diseases (CVD), and mortality [5-6]. While in MHD patients, the risk of mortality owing to excursions in magnesium levels has been largely neglected. Therefore, the relationship between serum Mg levels and mortality in patients undergoing MHD is worth exploring.

The serum Mg is closely related with serum potassium [7]. Mg plays a role in the active transport of calcium and potassium ions acrossing cell membranes, a process important to nerve impulse conduction, muscle contraction and normal heart rhythm [8]. Higher variability of serum potassium level suggested an increased risk of death [9]. However, few studies could determine whether serum Mg variability is associated with mortality in MHD patients. Therefore, we conducted this study to clarify the relationship between serum $\mathrm{Mg}$ baseline level, serum Mg variability and mortality in MHD patients.

\section{Patients and Methods}

\section{Patients}

Patients aged 18 years and older receiving regular MHD at Ningbo No. 2 Hospital between January 1, 2009 and August 31, 2016 were screened and enrolled. The inclusion criteria were dialysis duration over 3 months, currently in a stable condition, use of arteriovenous fistula and volunteering to participate. Exclusion criteria were incomplete data, lack of follow-up, proton pump inhibitors use at the time of enrollment. A follow up was conducted and ended upon patient death or transplantation. A standardized dialysis procedure was performed to all subjects with bicarbonate dialysis fluid running at $500 \mathrm{~mL} / \mathrm{min}$, dialysate flow and blood flow going between 200 and $300 \mathrm{~mL} / \mathrm{min}$. Dialysis concentration were as follows: sodium $137.8 \mathrm{mmol} / \mathrm{L}$, potassium $2.0 \mathrm{mmol} / \mathrm{L}$, calcium $1.5 \mathrm{mmol} / \mathrm{L}$ and magnesium $0.5 \mathrm{mmol} / \mathrm{L}$.

The study was approved by the Ethics Committee of Ningbo No. 2 Hospital.

\section{Data Collection}

Baseline clinical data included age, gender, the etiology of kidney disease, body mass index (BMI), dialysis duration, medication history, Kt/V measured by HD Adequest software (Huibaitong hemodialysis system, Beijing, China), and ultrafiltration volume. Pre-dialysis blood was taken including?white blood cell count (WBC), hemoglobin (Hb), platelet count 


\section{Kidney \\ Blood Pressure \\ Research}

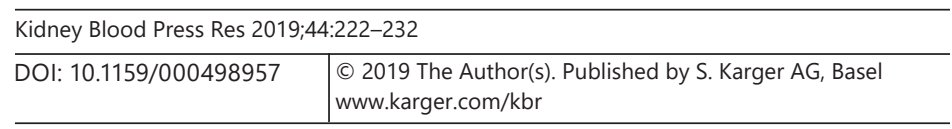

Wu et al.: Serum Magnesium Level and Its Variability with Mortality in MHD Patients

(PLT), serum calcium, phosphorus, potassium, sodium, Mg, intact parathyroid hormone (iPTH), serum albumin (Alb), ferroprotein and high-sensitivity C-reactive protein (hs-CRP). The baseline data was obtained during the first 3 months of hemodialysis. Each patient was follow-up every 3 months with serum Mg level measured at each visit.

Groups

The patients were divided into 2 groups based on serum $\mathrm{Mg}$ level, with mean value 1.00 $\mathrm{mmol} / \mathrm{L}$ : the lower Mg group (serum $\mathrm{Mg}<1.00 \mathrm{mmol} / \mathrm{L}$ ) and the higher Mg group (serum $\mathrm{Mg}$ $\geq 1.00 \mathrm{mmol} / \mathrm{L}$ ).

Serum magnesium variation was presented in forms of standard deviation (SD) and the coefficient of variation of serum magnesium (CVSM). CVSM was calculated as the ratio of SD to the mean of serum magnesium [9]. Patients were further divided into three classifications according to each tertile of magnesium CV: high variation group (CV $\geq 0.149 \mathrm{mmol} / \mathrm{L}$ ), middle variation group $(0.114 \mathrm{mmol} / \mathrm{L} \leq \mathrm{CV}<0.149 \mathrm{mmol} / \mathrm{L})$ and low variation group $(\mathrm{CV}<0.114$ $\mathrm{mmol} / \mathrm{L})$.

\section{Outcomes}

The study outcome data were cardiovascular and all-cause mortality, obtained from the history information system (HIS) at Ningbo No. 2 Hospital. CVD mortality includes deaths due to heart failure, ischemic heart disease, arrhythmia, and cerebrovascular disease.

\section{Statistical Analyses}

SPSS 22.0 was used for all statistical analyses. Continuous normally distributed data were presented as the mean $\pm \mathrm{SD}$, and Student's $t$ test or ANOVA analysis was used to compare the data within the groups. Non-normally distributed data were presented as the median (interquartile ranges), and comparisons within the groups were analyzed by Mann-Whitney U test or Kruskal-Wallis H test, as appropriate. Categorical data were presented as the number of cases and percentages, and Chi-Square analysis employed.

Cox regression analysis was adopted to evaluate independent predictors for all-cause and cardiovascular mortality. Risk factors were firstly assessed with univariate analysis and variables with significant relevance were further tested by multivariate analysis. KaplanMeier curves were performed and the log-rank tests were computed to compare curves of cardiovascular mortality and all-cause mortality in each group. Statistical significance was defined as a $p$ value $<0.05$. Data were presented as hazard ratio (HR) with $95 \%$ confidence intervals (CI).

\section{Results}

\section{Baseline Characteristics}

A total of 185 patients receiving regular MHD at Ningbo No. 2 Hospital between January 2009 and August 2016, were eligible. Among those, 16 patients were excluded because of incomplete data or lack of follow-up, and the remaining 169 patients were enrolled in this study.

The main characteristics of the 169 patients are summarized in Table 1, with 53.85\% $(91 / 169)$ being male, the mean age $60.20 \pm 15.64$ (21-89) years old, median dialysis duration $37.00(18.30,77.97)$ months. The leading cause of end-stage renal disease was glomerulonephritis (44.97\%), followed by diabetic kidney disease (24.26\%) and hypertension $(10.10 \%)$. The mean serum Mg level was $1.00 \pm 0.18 \mathrm{mmol} / \mathrm{L}$. 
Table 1. Baseline characteristics of 169 MHD patients according to serum magnesium level

\begin{tabular}{lcccc}
\hline Variable & Lower magnesemia group & Higher magnesemia group & $\mathrm{T} / \mathrm{Z} / \chi^{2}$ & $p$ value \\
\hline Subjects, $n$ & 94 & 75 & & \\
Baseline characteristics & & & & \\
$\quad$ Age, years & $65.27 \pm 13.68$ & $53.84 \pm 15.70$ & 5.051 & $<0.001^{*}$ \\
Gender, male (\%) & $52(55.32 \%)$ & $39(52.00 \%)$ & 0.185 & 0.667 \\
Dialysis duration, months & $20.77(12.63,29.48)$ & $78.22(55.07,109.60)$ & -10.284 & $<0.001^{*}$ \\
SpKt/V & $1.54 \pm 0.36$ & $1.66 \pm 0.30$ & -2.402 & $0.017^{*}$ \\
Ultrafiltration volume, mL & $2.19 \pm 0.87$ & $2.20 \pm 0.99$ & -0.117 & 0.907 \\
BMI, kg/m ${ }^{2}$ & $20.87 \pm 3.28$ & $20.65 \pm 3.34$ & 0.444 & 0.657 \\
MAP & $101.19 \pm 14.97$ & $100.17 \pm 17.98$ & 0.402 & 0.688 \\
Laboratory marker & & & & \\
WBC, $\times 10^{9} / \mathrm{L}$ & $6.10(4.90,7.60)$ & $5.05(4.00,6.40)$ & -3.026 & $0.002^{*}$ \\
Hb, g/L & $91.28 \pm 19.88$ & $87.09 \pm 18.14$ & 1.416 & 0.159 \\
PLT, $\times 10^{9} / \mathrm{L}$ & $177.00(131.00,234.00)$ & $151.50(109.00,199.00)$ & -2.386 & $0.017^{*}$ \\
Blood phosphorus, mmol/L & $1.62 \pm 0.65$ & $1.80 \pm 0.60$ & -1.859 & 0.065 \\
Blood calcium, mmol/L & $2.09(1.95,2.22)$ & $2.17(2.03,2.28)$ & -2.361 & $0.018^{*}$ \\
PTH, ng/L & $177.90(75.4,308.15)$ & $251.60(86.40,600.20)$ & -2.444 & $0.015^{*}$ \\
Serum potassium, mmol/L & $4.67 \pm 0.84$ & $4.88 \pm 0.83$ & -1.628 & 0.105 \\
Serum sodium, mmol/L & $139.19 \pm 3.52$ & $139.05 \pm 3.48$ & 0.255 & 0.799 \\
Blood magnesium, mmol/L & $0.87 \pm 0.09$ & $1.16 \pm 0.13$ & -16.979 & $<0.001^{*}$ \\
Blood magnesium CV & $0.13(0.10,0.17)$ & $0.13(0.11,0.15)$ & -0.066 & 0.947 \\
Serum albumin, g/L & $34.50(28.45,37.45)$ & $35.30(30.30,38.30)$ & -1.433 & 0.152 \\
Ferroprotein, $\mu \mathrm{Lg} / \mathrm{L}$ & $188.94(76.35,481.30)$ & $140.94(43.20,323.19)$ & -1.432 & 0.152 \\
CRP, mg/L & $4.30(1.72,12.68)$ & $1.69(0.04,7.43)$ & -3.527 & $<0.001^{*}$ \\
Prognosis & & & & \\
All-cause mortality, \% & $47(50.00 \%)$ & $22(29.33 \%)$ & 7.375 & $0.007^{*}$ \\
Cardiovascular mortality, \% & $17(18.09 \%)$ & $7(9.33 \%)$ & 2.622 & 0.105 \\
\hline * Significance at $p<0.05$ level. & & & & \\
\hline
\end{tabular}

There were 94 patients (55.62\%) in the lower Mg group and 75 patients (44.38\%) in the higher Mg group. In lower Mg group, the levels of age, WBC, PLT, hs-CRP were significantly higher, but dialysis duration, Kt/V, serum calcium, iPTH were significantly lower, compared with those in higher Mg group. During the follow up, 69 (40.83\%) patients died, 24 (34.78\%) of whom died of cardiovascular events. Compared with that in the higher Mg group, patients had a higher all-cause mortality in the lower Mg group (50.00 vs. $29.33 \%, p=0.007$ ) (Table 1).

According to serum magnesium CV, the patients were divided into three classifications as mentioned above. The dialysis duration and serum magnesium in the middle variation group were significantly higher, compared with those in the low variation group and the high variation group $(p<0.05)$. However, the other parameters showed no significant statistical differences among the three groups (Table 2).

The Association between Magnesium Baseline Level and Mortality

During the follow up, $69(40.83 \%)$ patients died. The causes of death for these 69 cases are shown in Table 3. Cardiovascular events (34.78\%) were the primary cause of death, followed by cerebrovascular disease (24.64\%) and sepsis cause (15.94\%) (Table 3).

The cumulative overall survival rate was $94.6 \pm 1.9 \%$ in the first year, $73.0 \pm 3.7 \%$ in the third year, and $63.3 \pm 4.3 \%$ in the fifth year. Cardiovascular survival rates in the first, third and fifth year were $98.1 \pm 1.1 \%, 90.1 \pm 2.6 \%$ and $81.9 \pm 3.8 \%$, respectively. 
Kidney

Blood Pressure

Research
Kidney Blood Press Res 2019;44:222-232

Wu et al.: Serum Magnesium Level and Its Variability with Mortality in MHD Patients

サํํㅇำ

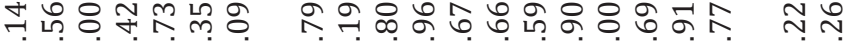

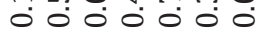

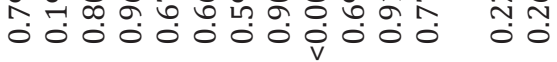

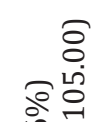

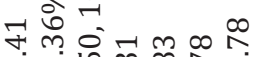

ம่

+1 200000

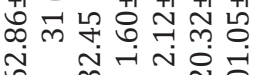

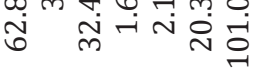

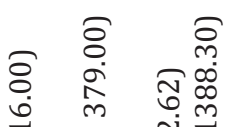

윽윻ํ

宊

ㄷํ용

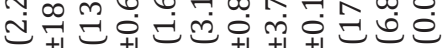

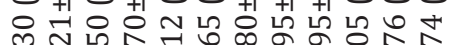

in

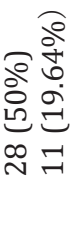

ำ

ธิ के ले

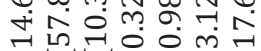

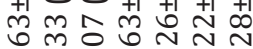

ठำ

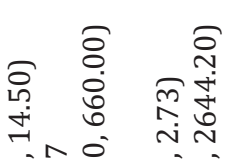

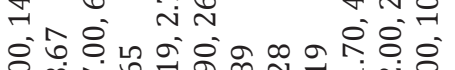

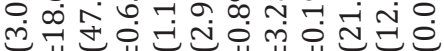

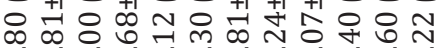

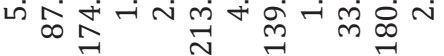

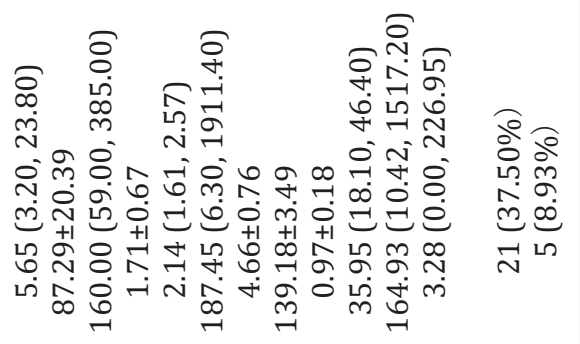

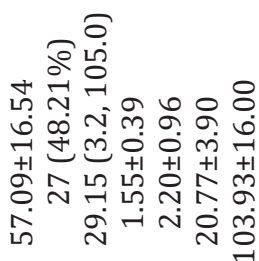

ஓे वे

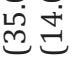

$\stackrel{\infty}{\infty}$

ริ)

ㄴํำ

Tom

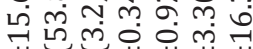

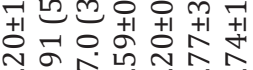

$\stackrel{\pi}{\stackrel{\pi}{0}}$

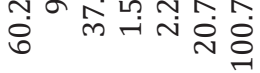

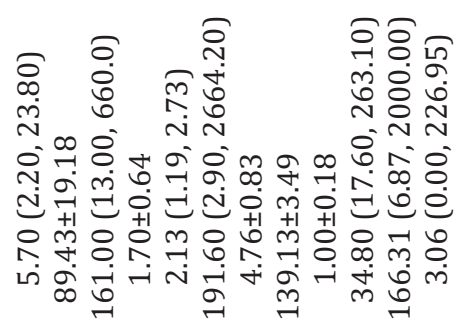

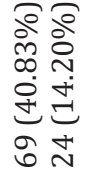

में

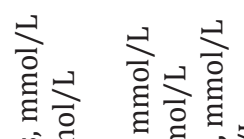

高

है है है

हो

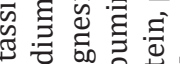

䒕记 
Table 3. The causes of death according to serum magnesium level

\begin{tabular}{lrll}
\hline Variable & $\begin{array}{l}\text { lower magnesemia } \\
\text { group (47) }\end{array}$ & $\begin{array}{l}\text { higher magnesemia } \\
\text { group (22) }\end{array}$ & $p$ value \\
\hline Cardiovascular disease & $15(31.91 \%)$ & $9(40.91 \%)$ & 0.465 \\
Cerebrovascular disease & $11(23.40 \%)$ & $5(22.73 \%)$ & 0.950 \\
Sepsis & $8(17.02 \%)$ & $3(13.64 \%)$ & 0.720 \\
Tumor & $6(12.77 \%)$ & $3(13.64 \%)$ & 0.920 \\
Others & $7(14.89 \%)$ & $2(9.09 \%)$ & 0.505 \\
\hline
\end{tabular}

Fig. 1. Kaplan-Meier curves for all-cause mortality according to the category of serum magnesium baseline.

Fig. 2. Kaplan-Meier curves for cardiovascular mortality according to the category of serum magnesium baseline.
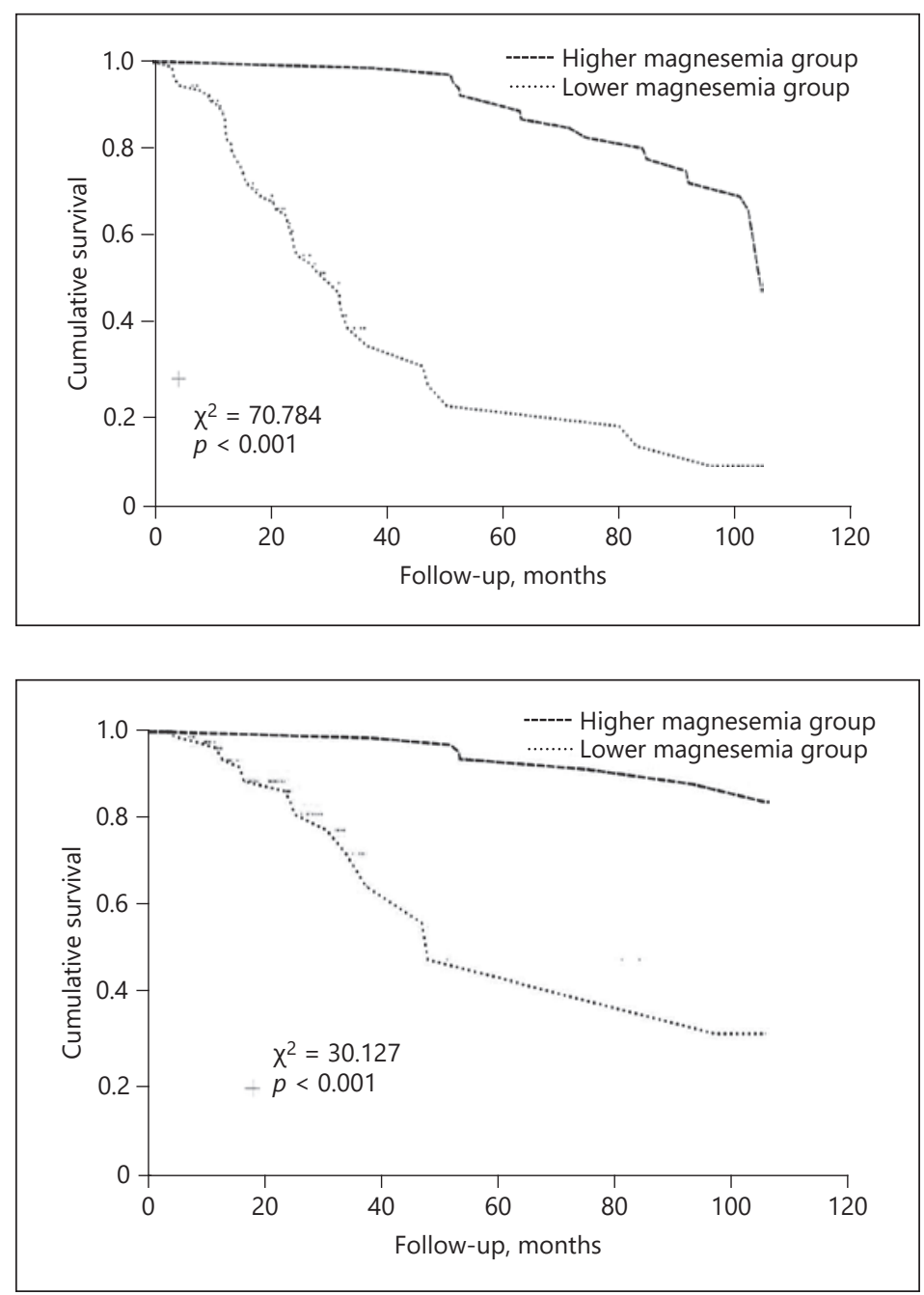

Kaplan-Meier curves showed that the patients in the lower Mg group had higher all-cause (log rank $=70.784, p<0.001)$ and cardiovascular mortality (log rank $=30.127, p<0.001)$ than patients in the higher Mg group (Fig. 1, 2)

The multivariate Cox regression analysis showed that lower $\mathrm{Mg}$ level was an independent factor for all-cause mortality as well as cardiovascular mortality (HR $=8.304,95 \%$ CI 4.25916.192, $p<0.001$; HR = 9.721, 95\% CI 3.251-29.066, $p<0.001$; respectively). In addition, age, low serum Alb and hs-CRP were also independent factors for all-cause mortality and cardiovascular mortality $(p<0.05)$ (Table 4$)$. 


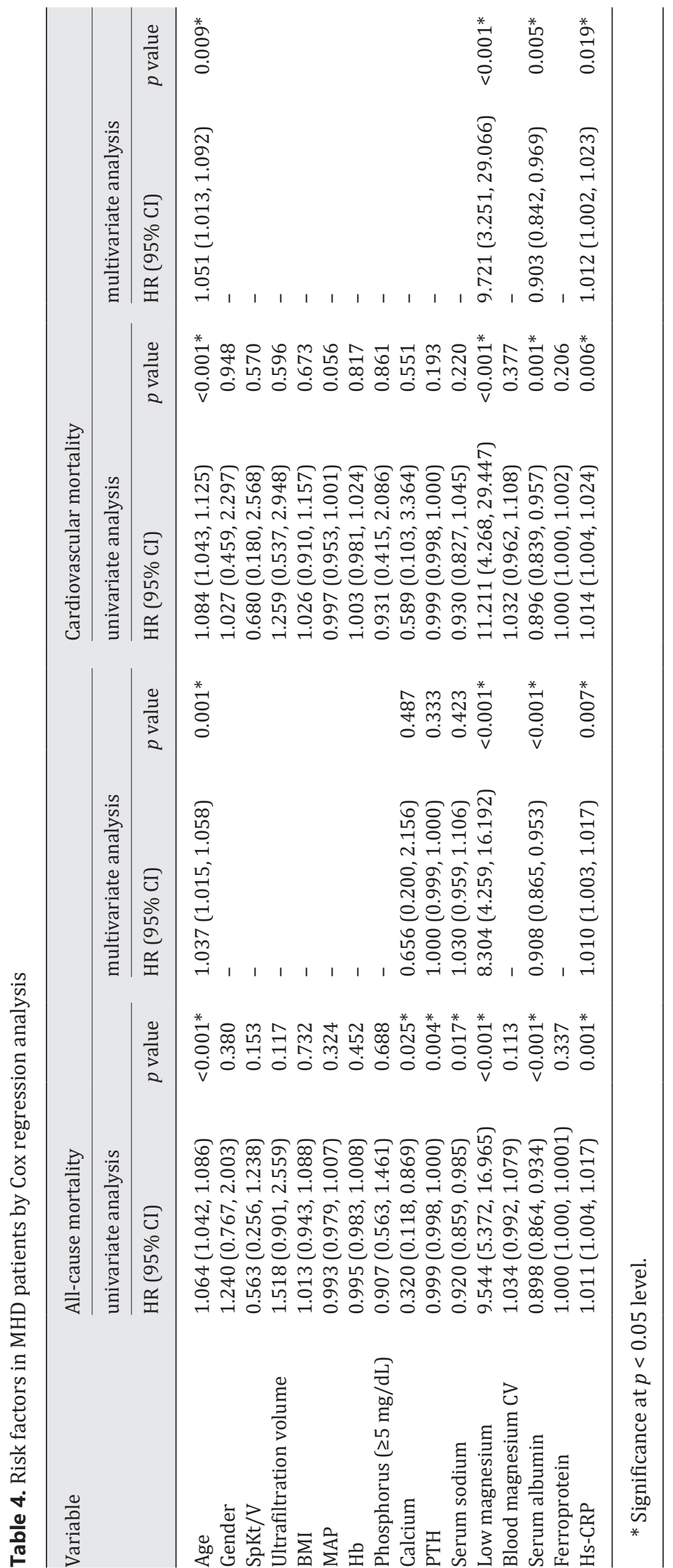


Fig. 3. Kaplan-Meier curves for allcause mortality according to the category of serum magnesium variability. Kaplan-Meier curves showed that the patients in the high variation group had higher all-cause mortality (log rank = 9.991, $p=0.002$ ) than that in the middle variation group, and slightly higher than that in the low variation group, though without significantly statistical difference (log rank $=1.542, p=0.241) . p<0.05$ comparing the high CV to the middle CV, $p<0.05$ comparing the high $\mathrm{CV}$ to the low CV, $p<0.05$ comparing the low $\mathrm{CV}$ to the middle $\mathrm{CV}$.

Fig. 4. Kaplan-Meier curves for cardiovascular mortality according to the category of serum magnesium variability. There was no significantly statistical difference between serum magnesium $\mathrm{CV}$ and cardiovascular mortality $(p>$ 0.05 ) in the MHD patients. $p<$ 0.05 comparing the high $\mathrm{CV}$ to the middle $\mathrm{CV}, p<0.05$ comparing the high $\mathrm{CV}$ to the low $\mathrm{CV}, p<0.05$ comparing the low $\mathrm{CV}$ to the middle CV.
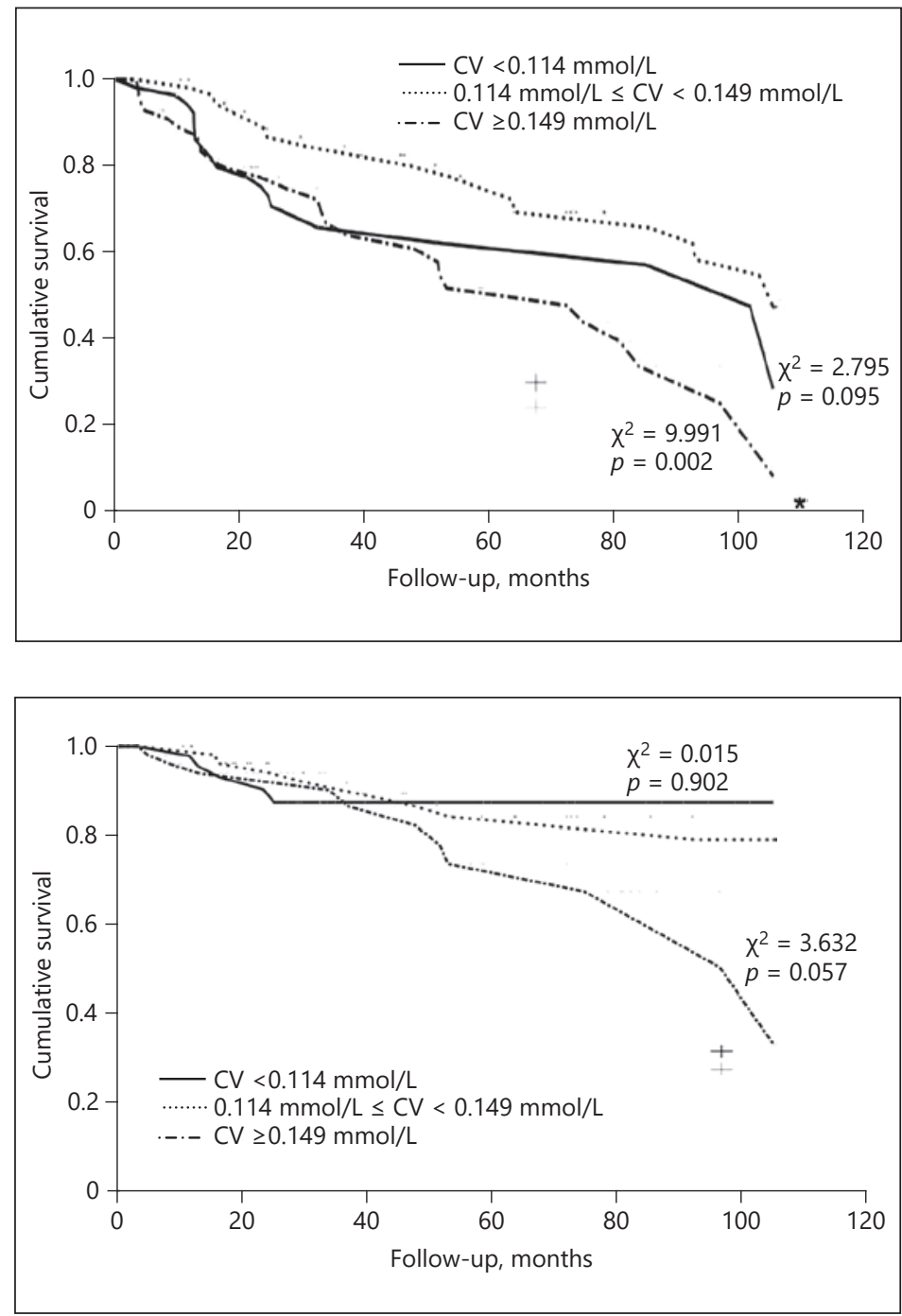

The Association between Magnesium Variability and Mortality

There were no significant statistical differences of all-cause and CVD mortality among these three groups (Table 2). Kaplan- Meier curves showed that the patients in the high variation group had a higher all-cause mortality (log rank $=9.991, p=0.002)$ than that in the middle variation group, and slightly higher than that in the low variation group, though without significantly statistical difference ( $\log$ rank $=1.542, p=0.241$ ) (Fig. 3). There was no significantly statistical difference between serum magnesium $\mathrm{CV}$ and cardiovascular mortality $(p>0.05)$ in the MHD patients. (Fig. 4)

However, in the univariate and multivariate Cox regression analysis, serum magnesium $\mathrm{CV}$ was not the independent factor for all-cause mortality or cardiovascular mortality.

\section{Discussion}

This study was intended to investigate whether serum Mg baseline level and its variability have an effect on all-cause and cardiovascular mortality in MHD patients. The results showed that patients with in lower Mg group had significantly different baseline character- 


\section{Kidney \\ Blood Pressure \\ Research}

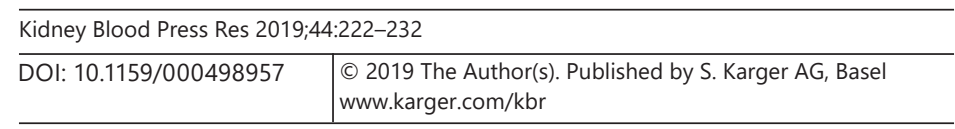

Wu et al.: Serum Magnesium Level and Its Variability with Mortality in MHD Patients

istics: greater age, higher hs-CRP and lower serum calcium and PTH. Moreover, a low serum $\mathrm{Mg}$ level independently predicted all-cause and cardiovascular mortality. However, the variability of magnesium level was not independently associated with the risk of death.

Mg is important in regulating certain aspects of cardiovascular system and also in survival [10]. A negative correlation between serum Mg level and mortality has been reported in peritoneal dialysis patients [11]. The other study showed that lower serum Mg level was significantly associated with increased all-cause and cardiovascular mortality in MHD patients, coinciding with earlier studies [12-16]. This relationship was further acknowledged by a meta-analysis study that found a significant inverse association between Mg intake and the risk of CVD events in different patients in 19 prospective studies including 532,979 participants [17]. Chronic Mg deficiency is associated with multifactorial cellular necrosis, accumulation of intracellular calcium, increased platelet aggregation, coronary vasoconstriction, atherogenesis, and cardiac arrhythmia [18].

The risk factors for hypomagnesemia in MHD patients are complex. The Mg content in the body is tightly regulated by an orchestrated interaction among the intestines, kidneys, and bones [19]. Hypomagnesemia is mainly caused by low Mg intake, enhanced urinary excretion, and reduced gastrointestinal absorption. Since urinary Mg excretion is mostly negligible among hemodialysis patients, hypomagnesemia of these patients is largely determined by dietary Mg intake as well as dialysate Mg concentrations. Under the same dialysate Mg concentration, serum Mg levels are well correlated with the dietary amount of Mg [20]. Luis et al. reported that the daily amount of Mg intake of hemodialysis patients is very low, and only $2 \%$ of patients consume Mg above the minimum requirement [21]. This is probably because magnesium-rich foods are also rich in potassium, which should be restricted for patients with end-stage kidney disease [22]. In lower Mg group, there was a higher proportion of elderly patients with a long-term poor appetite in general, which could be accompanied with malnutrition, an important cause of hypomagnesemia. Moreover, hypomagnesemia is associated with inflammation [23], which coincided with our study. Studies have suggested that increased inflammatory indicators including hs-CRP and circulating endothelin can be exacerbated by hypomagnesemia in HD patients [24]. Mg deficiency could induce high circulating amounts of IL-1, IL- 6 and TNF- $\alpha$, which can further stimulate free radical production in endothelial cells and circulation white blood cells [25]. A small-scale clinical study showed that magnesium treatment results in a significant reduction of serum malondialdehyde, an indicator of lipid peroxidation due to oxidative stress [26].

Long-term Mg supplementation has been reported to reduce carotid intima-medial thickness in dialysis patients [27]. Another analysis showed that maintaining a high Mg level was beneficial to improve cardiovascular prognosis of hemodialysis patients with hyperphosphatemia [28]. However, further studies are needed to clarify whether oral $\mathrm{Mg}$ supplement for hypomagnesemia or higher Mg concentration in the dialysate would reduce risk of mortality in MHD patients.

It has been reported that the variability of hemoglobin [29], serum calcium and phosphorus [30], as well as variability of serum potassium levels [9] are closely associated with clinical outcomes. However, few studies have investigated Mg variability in MHD patients. In this study, we found that higher serum magnesium CV had higher all-cause mortality than that in the middle variation group, and slightly higher than that in the low variation group in Kaplan- Meier curves. However, there was no difference of all-cause mortality in the univariate and multivariate Cox regression analysis, serum magnesium CV was not the independent factor for all-cause mortality and cardiovascular mortality. It seemed that the $\mathrm{Mg}$ baseline outweighed the Mg variation to predict the mortality in MHD patients. However, this is a retrospective study with a relatively small sample size. Further studies need to be conducted. 


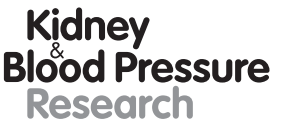

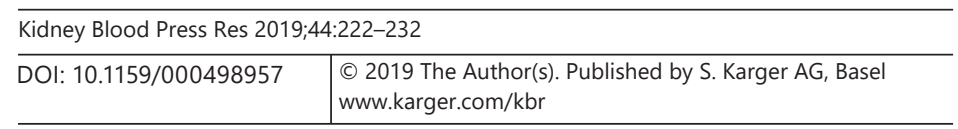

Wu et al.: Serum Magnesium Level and Its Variability with Mortality in MHD Patients

This study is a retrospective and observational database study and some limitations need to be noticed. First, all subjects enrolled are recruited from one single center, leading to a relatively small sample size. Second, there is a potential selection bias when we evaluated the association between serum magnesium variability and mortality. Because the enrollment criterion was patients receiving MHD for more than 3 months with at least four check-ups of serum magnesium. However certain patients with relatively lower or higher serum magnesium levels might have died before completing the 3-month therapy or four serum magnesium check-ups, making this part of data excluded for analysis. Therefore, the study may underestimate the negative roles of serum magnesium variability in mortality. Third, factors affecting serum magnesium levels, such as dietary intake, loss via dialysate and urine, were not assessed in the present study.

\section{Conclusions}

Patients on dialysis have a mortality rate higher than the general population. In this study, the lower serum magnesium baseline level is independently correlated with all-cause mortality and cardiovascular mortality in MHD patients. However, the variability of serum magnesium level was not independently associated with the risk of death. Therefore, prospective studies with bigger sample size are needed for further study.

\section{Acknowledgements}

We thank Ningjun Shao at the Department of Nephrology, Ningbo No. 2 Hospital for his help in amending the manuscript.

Study design: QL, LPW, KDC; Data analysis: LPW, KDC, LLW, YH; Article drafting: QL, LPW, KDC, LLW, YH; All authors approved the final version of the manuscript.

Ethical approval: The study was approved by the Ethics Committee of Ningbo No. 2 Hospital (PJ-NBEY-KY-2018-006-01).

Funding: This study was sponsored by Medical Scientific Research Foundation of Zhejiang Province, China (2019KY174).

\section{Disclosure Statement}

The authors have no relevant financial or non-financial competing interests to declare in relation to this article.

\section{References}

1 U.S. Renal Data System. USRDS 2017 Annual Data Report: Healthy people 2020.URL: https://www.usrds. org/2017/view/ HP2020. Aspx.

2 Brunelli SM, Du Mond C, Oestreicher N, Rakov V, Spiegel DM. Serum potassium and short-term clinical outcomes among hemodialysis patients: impact of the long interdialytic interval. Am J Kidney Dis. 2017 Jul; 70(1):21-9.

3 Poulikakos D, Marks V, Lelos N, Banerjee D. Low serum sodium is associated with protein energy wasting and increased interdialytic weight gain in haemodialysis patients. Clin Kidney J. 2014 Apr;7(2):156-60.

4 João Matias P, Azevedo A, Laranjinha I, Navarro D, Mendes M, Ferreira C, et al. Lower serum magnesium is associated with cardiovascular risk factors and mortality in haemodialysis patients. Blood Purif. 2014;38(34):244-52. 
5 Li L, Streja E, Rhee CM, Mehrotra R, Soohoo M, Brunelli SM, et al. Hypomagnesemia and mortality in incident hemodialysis patients. Am J Kidney Dis. 2015 Dec;66(6):1047-55.

6 Reffelmann T, Ittermann T, Dörr M, Völzke H, Reinthaler M, Petersmann A, et al. Low serum magnesium concentrations predict cardiovascular and all-cause mortality. Atherosclerosis. 2011 Nov;219(1):280-4.

7 Pan WH, Lai YH, Yeh WT, Chen JR, Jeng JS, Bai CH, et al. Intake of potassium- and magnesium-enriched salt improves functional outcome after stroke: a randomized, multicenter, double-blind controlled trial. Am J Clin Nutr. 2017 Nov;106(5):1267-73.

8 Rosanoff A, Weaver CM, Rude RK. Suboptimal magnesium status in the United States: are the health consequences underestimated? Nutr Rev. 2012 Mar;70(3):153-64.

9 Xu Q, Xu F, Fan L, Xiong L, Li H, Cao S, Lin X, Zheng Z, Yu X, Mao H. Serum potassium levels and its variability in incident peritoneal dialysis patients: associations with mortality. PLoS One. 2014;27;9(1): e86750.

10 Navarro-González JF, Mora-Fernández C, García-Pérez J. Clinical implications of disordered magnesium homeostasis in chronic renal failure and dialysis. Semin Dial. 2009 Jan-Feb;22(1):37-44.

11 Cai K, Luo Q, Dai Z, Zhu B, Fei J, Xue C, et al. Hypomagnesemia is associated with increased mortality among peritoneal dialysis patients. PLoS One. 2016 Mar;11(3):e0152488.

12 Tin A, Grams ME, Maruthur NM, Astor BC, Couper D, Mosley TH, et al. Results from the Atherosclerosis Risk in Communities study suggest that low serum magnesium is associated with incident kidney disease. Kidney Int. 2015 Apr;87(4):820-7.

13 Van Laecke S, Nagler EV, Verbeke F, Van Biesen W, Vanholder R. Hypomagnesemia and the risk of death and GFR decline in chronic kidney disease. Am J Med. 2013 Sep;126(9):825-31.

14 Sakaguchi Y, Fujii N, Shoji T, Hayashi T, Rakugi H, Isaka Y. Hypomagnesemia is a significant predictor of cardiovascular and non-cardiovascular mortality in patients undergoing hemodialysis. Kidney Int. 2014 Jan;85(1): 174-81.

15 Yu L, Li H, Wang SX. Serum magnesium and mortality in maintenance hemodialysis patients. Blood Purif. 2017; 43(1-3):31-6.

16 João Matias P, Azevedo A, Laranjinha I, Navarro D, Mendes M, Ferreira C, et al. Lower serum magnesium is associated with cardiovascular risk factors and mortality in haemodialysis patients. Blood Purif. 2014;38(34): $244-52$

17 Qu X, Jin F, Hao Y, Li H, Tang T, Wang H, et al. Magnesium and the risk of cardiovascular events: a meta-analysis of prospective cohort studies. PLoS One. 2013;8(3):e57720.

18 Tzanakis IP, Oreopoulos DG. Beneficial effects of magnesium in chronic renal failure: a foe no longer. Int Urol Nephrol. 2009;41(2):363-71.

19 de Baaij JH, Hoenderop JG, Bindels RJ. Magnesium in man: implications for health and disease. Physiol Rev. 2015 Jan;95(1):1-46.

20 Wyskida K, Witkowicz J, Chudek J, Więcek A. Daily magnesium intake and hypermagnesemia in hemodialysis patients with chronic kidney disease. J Ren Nutr. 2012 Jan;22(1):19-26.

21 Luis D, Zlatkis K, Comenge B, García Z, Navarro JF, Lorenzo V, et al. Dietary quality and adherence to dietary recommendations in patients undergoing hemodialysis. J Ren Nutr. 2016 May;26(3):190-5.

22 Sakaguchi Y, Hamano T, Isaka Y. Effects of magnesium on the phosphate toxicity in chronic kidney disease: time for intervention studies. Nutrients. 2017 Feb;9(2):112.

23 Weglicki WB. Hypomagnesemia and inflammation: clinical and basic aspects. Annu Rev Nutr. 2012 Aug;32(1): 55-71.

24 Pakfetrat M, Malekmakan L, Roozbeh J, Haghpanah S. Magnesium and its relationship to C-reactive protein among hemodialysis patients. Magnes Res. 2008 Sep;21(3):167-70.

25 Weglicki WB, Dickens BF, Wagner TL, Chmielinska JJ, Phillips TM. Immunoregulation by neuropeptides in magnesium deficiency: ex vivo effect of enhanced substance P production on circulating T lymphocytes from magnesium-deficient mice. Magnes Res. 1996 Mar;9(1):3-11.

26 Ariza AC, Bobadilla N, Fernández C, Muñoz-Fuentes RM, Larrea F, Halhali A. Effects of magnesium sulfate on lipid peroxidation and blood pressure regulators in preeclampsia. Clin Biochem. 2005 Feb;38(2):128-33.

27 Turgut F, Kanbay M, Metin MR, Uz E, Akcay A, Covic A. Magnesium supplementation helps to improve carotid intima media thickness in patients on hemodialysis. Int Urol Nephrol. 2008;40(4):1075-82.

28 Sakaguchi Y, Fujii N, Shoji T, Hayashi T, Rakugi H, Iseki K, et al.; Committee of Renal Data Registry of the Japanese Society for Dialysis Therapy. Magnesium modifies the cardiovascular mortality risk associated with hyperphosphatemia in patients undergoing hemodialysis: a cohort study. PLoS One. 2014 Dec;9(12):e116273.

29 Sumida K, Diskin CD, Molnar MZ, Potukuchi PK, Thomas F, Lu JL, et al. Pre-end-stage renal disease hemoglobin variability predicts post-end-stage renal disease mortality in patients transitioning to dialysis. Am J Nephrol. 2017;46(5):397-407.

30 Ulusoy S, Ozkan G, Guvercin B, Yavuz A. The relation between variability of intact parathyroid hormone, calcium, and cardiac mortality in hemodialysis patients. Artif Organs. 2016 Nov;40(11):1078-85. 